\title{
PULMONARY ARTERIO-VENOUS FISTULA
}

\section{Review of World Literature and Report on two additional Cases}

\author{
By A. W. Fawcett, F.R.C.S. and B. S. Dhillon, F.R.C.S. \\ The Royal Infirmary, Sheffield
}

Two cases of pulmonary arterio-venous fistula are presented. There are 165 cases reported in the medical literature. ${ }^{1}$

Pulmonary arterio-venous fistula is a congenital shunt between the arteries and veins of the lung. This single pathological condition has been designated by different names. ${ }^{2}$ Most authorities prefer to call this anomaly as arterio-venous fistula rather than arterio-venous aneurysm. ${ }^{3}$ The pulmonary arterio-venous fistula may be found in any part of the lung and may be multiple involving both lobes or lungs., 5 It is variable in size; it may be a small area of capillary haemangioma, which produces no symptoms and clinical signs or it may occupy the whole lobe.

In the majority of cases the feeding branches are from the pulmonary artery. The blood that enters the fistula remains unoxygenated. This unoxygenated blood is returned back to the left side of the heart via the draining pulmonary vein. The effect on the individual will depend on the amount of unoxygenated blood returned to the systemic arterial circulation. When the shunt is large enough to produce arterial oxygen unsaturation it gives rise to cardinal diagnostic findings, i.e. Dyspnoea, cyanosis, clubbing of the digits and polycythaemia. When the shunt is small no noticeable effect results and all the classical clinical features may be absent except for the abnormal shadow on the radiograph of the chest. ${ }^{12,14}$

The frequent occurrence of aberrant and accessory pulmonary arteries and veins has been emphasized.4, 15 The feeding branch may be a bronchial artery, ${ }^{3}$ or it may arise separately from the descending aorta ${ }^{16}$. If the feeding branch arises from the systemic arterial circulation, cyanosis and polycythaemia will be absent.

Case I. Mrs. X. Hospital No. 383197. Aged 26 years.

Admitted to the Royal Infirmary, Sheffield, on February 4, 1953. She gave a history of cough and three attacks of haemoptysis over the last three months. During one of these attacks of

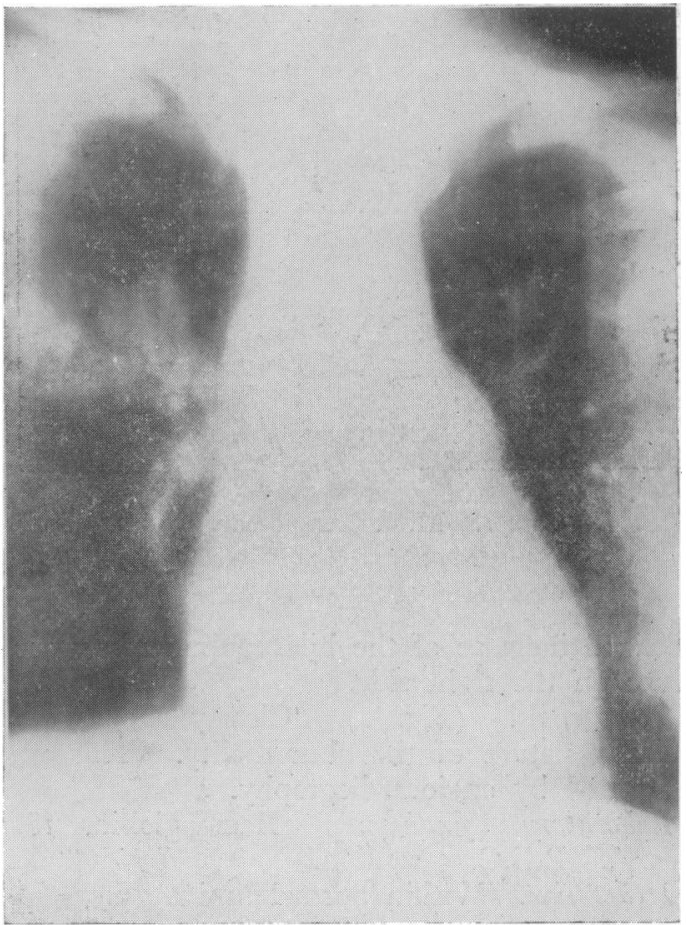

FIg. I.-Case I. M.K. Tomgram I I c.m. cut.

haemoptysis she collapsed and became unconscious. She is supposed to have lost about $\frac{1}{2}$ pint blood.

On examination. She was a well nourished young woman, who did not complain of shortness of breath. She showed grade I cyanosis and had clubbing of the fingers. There was no evidence of cutaneous and mucosal haemangioma. A loud, harsh systolic murmur and soft diastolic murmur were heard just below the right clavicle. The murmurs were exo-cardial. She was 12 weeks pregnant.

Raviograph of the chest. Showed an abnormal shadow in the right upper lobe. There was 


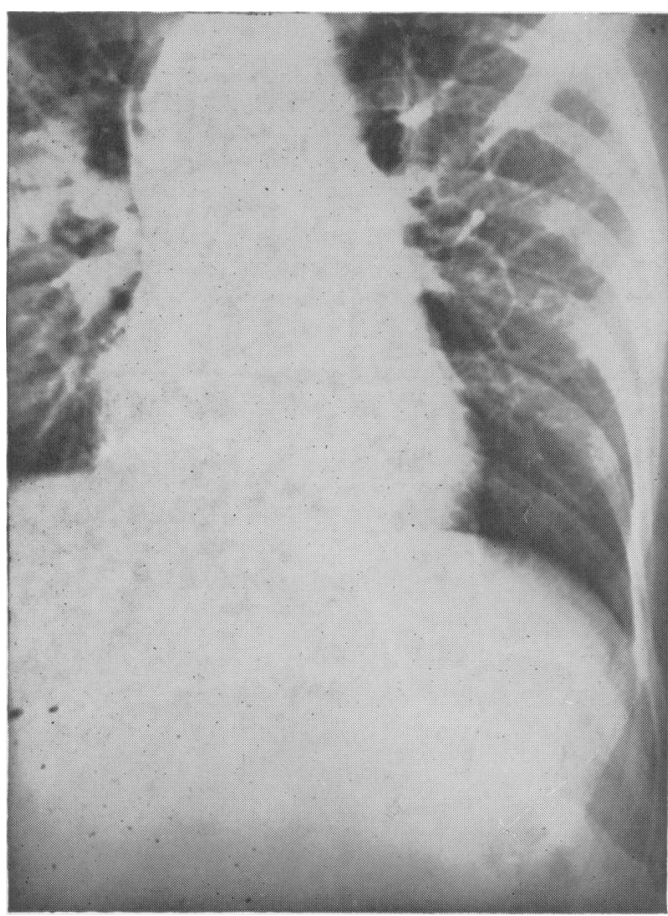

Fig. 2.-Case I. M.K. Angio-cardiogram (4 sec.).

localized increase of the hilar pulmonary vasculature on the right side.

Tomograms. (Fig. I). Clearly showed the vascular nature of the abnormality. This was confirmed by angiocardiography.

Laboratory findings. Haemoglobin, 18.4 gms. \%. R.B.C. 5 million.

Heart size. Within normal limits.

Blood pressure. $\mathrm{I} 30 / 100$.

On February 17, 1953, Mr. A. W. Fawcett carried out right upper lobectomy. At operation, a thrill could be felt and a fistula appeared to involve most of the right upper lobe.

Her post-operative progress was uneventful. She was seen in the follow-up clinic on December 20, 1955. Her cyanosis and clubbing had disappeared. There were no further episodes of haemoptysis. Physical examination and screening of the chest revealed nothing abnormal.

Case 2. Mr. X. Hospital No. 325978. Aged 48 years.

This patient was referred to the thoracic unit on October 8 , 1952, with a history of repeated haemoptyses and fainting attacks over the last two months.

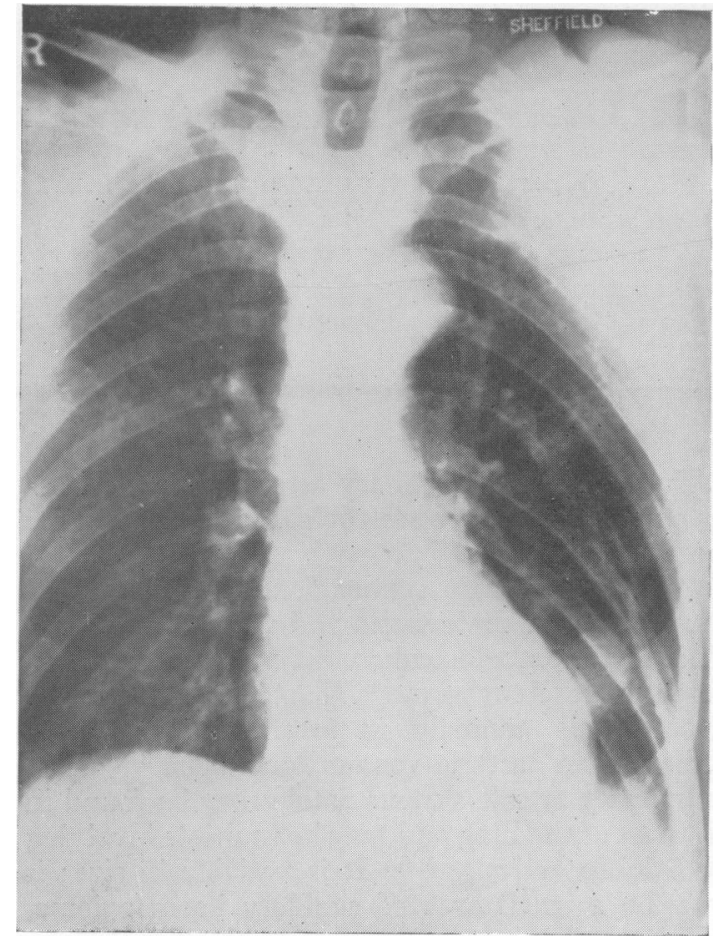

FIG. 3.-Case 2. Straight X-ray chest. Before second operation.

On looking through his notes on his first admission, the patient did not complain of shortness of breath. Physical examination revealed an exocardial systolic murmur in the left 5 th and 6 th intercostal space, in the mid axillary line. There were no other abnormal physical findings noted on his first admission.

Laboratory findings. Haemoglobin, 13.8 gms. \% (October IO, 1952.)

Radiograph of the chest. Showed an abnormal rounded opacity in the lef: lowir lobe.

Tomograms. October 14, 1952. Did not show any vessels connected with the rounded shadow at the left base.

On October 16, 1952, left thoracotomy was carried out. "No evidence of any pathological condition could be found in the left lower lobe". The chest was closed.

He was discharged home on November I4, 1952, and resumed his work. On November 2, I955, he suddenly coughed up about $\frac{1}{4}$ pint of blood and fainted. He was re-admitted on November 8, I955. He reluctantly admitted that he has been dyspnoeic for the past few years. On physical examination he showed Grade I cyanosis, clubbing of the fingers and telangiectasis of the 


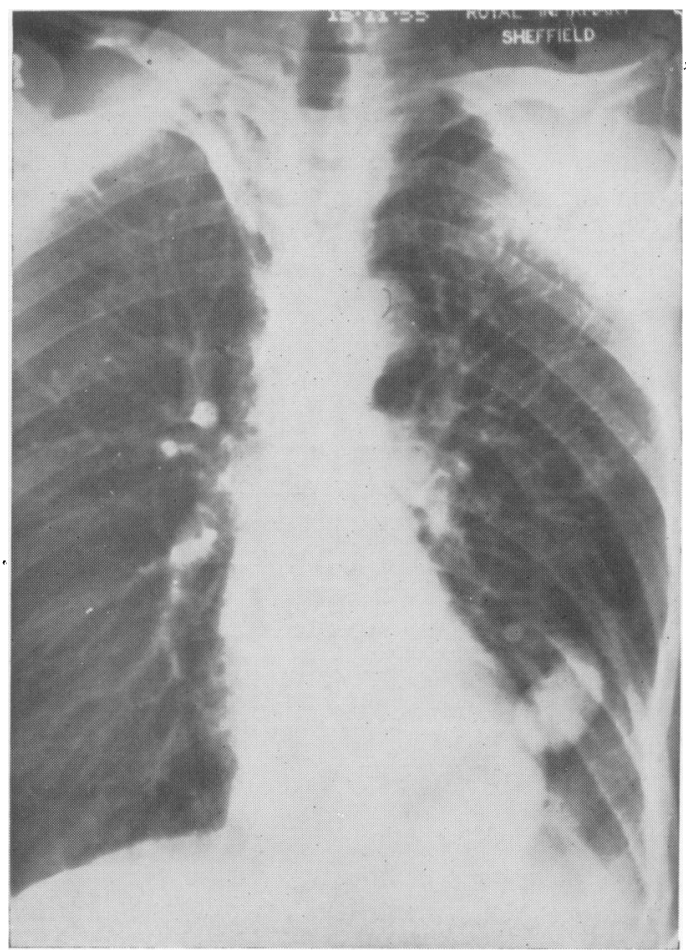

FIG. 4.-Case 2. Angio-cardiogram (5 sec.).

mucous membrane of the mouth. A loud, harsh systolic murmur could be heard in the left $5^{\text {th }}$ and 6th intercostal space in the mid axillary line.

Radiograph of the chest. November I 5, 1955. Showed a rounded opacity in the left lower lobe. The lesion had remained stationary in size over the past three years. (Fig. 3.)

Angiocardiography. Confirmed the diagnosis of the arterin-venous fistula. (Fig. 4).

Laboratory findings. Haemoglobin, 13.6 gms. $\%$.

On November I7, 1955, left lower lobectomy was carried out by Mr. B. S. Dhillon. At operation there was nothing abnormal to be felt in the left lower lobe. Trial clamping of the inferior pulmonary vein during operation caused distention of the fistula enabling it to be felt easily. A marked thrill could also be palpated. The dissection of the hilum revealed that branches of the pulmonary artery were abnormal in number and course. There were two small arteries opening into the fistula from the left upper lobe. His post-operative progress was smooth. The exo-cardial systolic murmur disappeared and he was discharged home on November 30 , 1955.

In both of our cases the family history was carefully taken but no abnormality could be elicited in any of their relatives. There is a familial history of the disease in $15 \%$ of the reported cases 4 , and about $40 \%$ of the reported cases also had associated cutaneous and mucosal haemangiomas and telangiectasis ${ }^{4}$.

Pulmonary arterio-venous fistulae have definite relation to hereditary haemorrhagic telangiectasis. (Rendu-Osler-Weber's disease ${ }^{6}$.) In many cases this may not be obvious, but typical cases of Rendu-Osler-Weber's disease may have pulmonary arterio-venous fistulae. The gross appearance of two resected specimens was of distended globular sacs. In case 2, multiple branches of the pulmonary artery opened into the thin walled sac. This sac was directly continuous with a large vein which drained into the inferior pulmonary vein. The arteries and veins were very thin walled.

In our two cases haemoptysis induced them to seek medical advice. The arterio-venous fistula may bring about patient's death by rupture into the bronchus, or into the pleural cavity ${ }^{6,8,18}$.

Dyspnoea. Was absent in our first case, and Case 2 admitted shortness of breath after careful enquiry. When dyspnoea develops, this can be progressive and incapacitating.

Cyanosis. Mild cyanosis was present in both cases. The cyanosis depends on the amount of unoxygenated blood returning to the systemic arterial circulation. The cyanosis may be entirely absent in a patient with small right to left shunt, but if there is a large shunt intense cyanosis can develop. Patients who become anaemic due to repeated blood loss may not show any cyanosis. The cyanosis becomes masked by anaemia?

Clubbing of the digits. Clubbing of the fingers was present in both cases.

Secondary polycythaemia. The chronic anoxia causes secondary polycythaemia to develop.

Nervous symptoms in the form of headaches, faintness, numbness, hemiplegia and convulsions may occur, especially in patients with marked cyanosis. The arterial oxygen unsaturation and polycythaemia are probably responsible for nervous symptoms. Lindgren ${ }^{10}$ has made the suggestion that air emboli are responsible for these symptoms. In our two patients, fainting attacks were directly related to the loss of blood by haemoptysis.

These cases are liable to develop brain abscess $^{3}, 11,12,19$ due to paradoxical embolism arising from infective endartritis of the fistula. A vascular murmur may be heard over the fistula. The murmur is exo-cardial. A loud, harsh systolic murmur and a soft diastolic murmur was heard over the right upper lobe in the first case and a loud, harsh systolic murmur was heard over the left lower lobe in our second case. 
The other disease which may be confused with pulmonary arterio-venous fistula are as follows:-

Congenital heart disease. The presence of dyspnoea, cyanosis, clubbing of the fingers, may lead to the erroneous diagnosis of congenital heart disease ${ }^{20}$. In congenital heart disease, presence of cardiac murmurs and abnormal configuration of heart should lead to correct diagnosis. These cases which have marked compensatory polycythaemia may be misdiagnosed as Polycythaemia Rubra Vera. This may be further complicated by appearance of multiple oval opacities in the lung fields in cases of polycythaemia rubra vera. These opacities are transient; repeat X-ray of the chest and bone marrow examination will help in arriving at the correct diagnosis. The occurrence of haemoptysis and finding of an abnormal shadow in the X-ray of the chest may lead to the diagnosis of pulmonary tuberculosis ${ }^{13}$. The sputum is negative for tubercle bacilli. Tomograms and cardioangiogram will help to establish the correct diagnosis. Benign and malignant tumours may be suspected when a density is seen on the chest X-ray. Once again tomograms and cardioangiography will help to establish the diagnosis.

\section{Radiological Diagnosis}

The straight radiograph of the chest shows an abnormal shadow which may be situated in any part of the lung. A localised increase of the hilar pulmonary vasculature may suggest pulmonary arterio-venous fistula ${ }^{3}$. This was seen in our first case.

The screening may show abnormal vascular pulsation of the lesion. This was clearly seen in our second case. With the valsalva procedure, the fistula distinctly diminished in size. Tomograms are of great help. They may clearly demonstrate the vessels connecting with the fistula. In our first case, the diagnosis was confirmed by tomography, though angiocardiography was carried out to exclude other fistulae in the lungs. In our second case Tomography did not prove helpful but the diagnosis was confirmed by angiocardiography.

Angiocardiography. There is general agreement that angiocardiography not only confirms the diagnosis but helps to exclude multiple and bilateral pulmonary arterio-venous lesions. We prefer multiple serial large films. The exposures are started two seconds after the beginning of the injection and are continued until the eighth second. The afferent and efferent connections of the pulmonary arterio-venous fistula are clearly demonstrated. Nine films are exposed during this interval of six seconds.

The pulmonary arterio-venous fistula may remain stationary for years. Our second case wass observed for three years. There was no increase in the size of the fistula. Frequently there is definite tendency towards progression. There is a definite risk of rupture of the fistulae into the bronchus or into the pleural cavity leading tofatal haemorrhage. The dyspnoea can be inca $\vec{F}$ pacitating and the course of the disease may be further complicated by cerebral disturbances and even brain abscess.

\section{Treatment}

The ideal treatment is surgical excision of the fistula. In our two cases, surgery was undertaken. because they had several attacks of minor haemop을 tyses and profuse haemoptysis on one occasion $\vec{\omega}$ These are ideal cases which give excellent results $\mathrm{Glen}^{21}$, et al, advocate surgery even in asympo tomatic cases. With the modern anaethesia anc. surgical technique "the risk of lobectomy and segmental resection is far less than the morbiditjw and mortality of complications, like brain abscesso haemoptysis and cerebral thrombosis due to polycythaemia $^{3}$ '

The cyanosis, dyspnoea and polycythaemia usually disappear following surgery ${ }^{4}, 22$. The type of surgical procedure carried out depends upon the size of the fistula. It is ideal to excise the fistula either by local excision, segmental resectr tion, lobectomy or pneumonectomy. If fistulae are multiple and bilateral it is imperatise that as little of the lung tissue as possible shoutes be sacrificed. The opposite side can be safelyo dealt with after an interval of a few months ${ }^{5}$.

\section{Summary}

Two patients with pulmonary arterio-venous fistula are reported. One of these patients was a young woman who was 12 weeks pregnant. Both patients had a lobectomy done with good result:

\section{REFERENCES}

I. DIENEMANN, G., Munchen. med. Wchnschi., 97, 818-820.

2. MURI, J. W. (I955), The American Fournal of Surgery, 89, No. I, 265-269.

3. STEINBERG, I., and McCLENAHAN, J. (1 955), The American?.

4. SLOAN, R. D., and COOLEY, R. N. (1953), American Fournalo

Roentgenal, 70, 183-210.

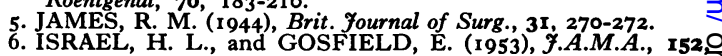
40-4I.

7. JAMES, RONALD, British Heart fournal, XVI, 34-37.

8. ERF, L. A., etc., American Heart fournal, 38, 766-774.

9. CAPPON, D. (1945), British Med. Fournal, 50, 440.

ro. LINDGREN, E. (1946), Acta Radiol. Stock., 27, 585.

I I. MURI, J. W. (1953), Disease of Chest, 24, 49-65.

12. WOODEHOUSE, G. E. (1948), Fournal of Thor. Surg., I7, 4O8-4I5.

13. FORSEE, J. H., etc. (1950), Ann. Surg., 131, 418-423.

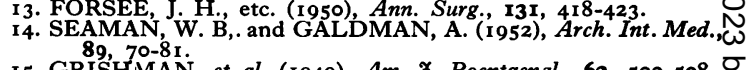

15. GRISHMAN, et al. (1949), Am. F. Roentgenal., 62, 500-508 16. WATSON, W. L. (1947), Surgery, 22, 9 19-929.

17. BARNES, C. G., et al. (1948), Thorax, 3, 148-160.

18. RODES, C. B. (1938), fournal Amer. Med. Assoc., r1o, 52 1-531 · 19. STERN, W. E., and NAFFZIGER, H. C., Ann. Surg., 138 , s 20. $\mathrm{BAKER}$-53I.

I GEN, C., and TROUNCE, J. (r 949), British Heart fournal, XI. T . FARRISON, C. S. and STEINBERG, I. (I953), Ann. Surg., 138, 886-891.

22. HEPBURN, J., and DAUPHINER, J. A. (I942), Am. F.M. Sc., $\stackrel{\vec{D}}{\mathrm{Q}}$ 204, 68I-685. 